\title{
Evaluation of the involvement of service users in post-qualifying social work education: Expected and unexpected results
}

\author{
Helen M Burrows ${ }^{1}$
}

\begin{abstract}
There is a long policy and tradition of service users being involved in the education of social work students and post-qualifying candidates, and they are recognised as educators in their own right, however there appears to have been limited measurement of the impact of service user educator involvement in post-qualifying education on practice, and ultimately on outcomes for end service users. A collaborative partnership between service user educators, practitioners and academics carried out research in this area in four local authorities in the English East Midlands (Equally Experienced Research Group, 2011); whilst it was found that direct service user educator input had a positive impact on candidates' practice, some unexpected and somewhat surprising responses arose. Interviews with candidates' line managers identified that there appeared to be significantly less active evaluation of outcomes for service users than we had assumed would be the case.

This paper initially sets the context for considering these responses by outlining the research undertaken, and considering how post-qualifying education as a whole might be evaluated as making a difference to practice. The second part of the paper looks at wider issues of evaluating practice and organisational service delivery. Methods used for measuring service user outcomes will be considered, alongside consideration of the active participation of service users in developing individual practice and agency service provision.
\end{abstract}

Keywords: social work education; post-qualifying; service user; practice; evaluation; partnership; social justice

1. Senior Lecturer, Division of Social Work, Health and Social Care and Counselling, Nottingham Trent University, UK

Address for correspondence: Helen M. Burrows, Division of Social Work, Health and Social Care and Counselling, Nottingham Trent University, Burton Street, Nottingham NG1 4BU, UK. helen.burrows@ntu.ac.uk

Date of publication (online): 30th August 2012 


\section{Introduction}

Post-Qualifying [PQ] Social Work education in the United Kingdom is Continuing Professional Development [CPD] education offered to fully qualified social workers to enable them to consolidate and develop their skills, values and knowledge in specialist areas of practice, at Specialist, Higher Specialist and Advanced levels. The ultimate aim of PQ education is, broadly, to optimise outcomes for service users through practitioner development, and Higher Education Institutes (HEIs) generally offer programmes specialising in one of three areas of practice: Adult Services, Mental Health Practice, or Children and Families practice. Leadership and Management, and Practice Education specialist programmes may be taught across the three main practice areas. The author's university is one of the main providers of the Specialist Post-Qualifying Award in Child Care Practice, teaching 11\% of candidates nationally between 2006 and 2009 (GSCC 2010 p.63). Around 30 candidates complete the Specialist level programme each year, with in excess of 100 candidates annually passing the Consolidation module, which is an entry requirement for the Specialist Award.

The programme is currently regulated by the General Social Care Council [GSCC] through their Post-qualifying framework for social work education and training (GSCC 2009) for England, though it will move soon to regulation by the Health Professions Council when the General Social Care Council is disbanded as part of the broad sweep of social work reform in 2012. The framework stipulates that:

In order to ensure that user and carer involvement is at the heart of the PQ system, arrangements for user and carer participation and involvement must be comprehensive. This means that these arrangements must be an integral part of arrangements for regional, sub-regional, local planning and commissioning of programmes, ensuring that the profile of training needs draws on user and carer voices and experiences. It also means that user and carer involvement and participation needs to be a feature of programme design and programme delivery. This will include involvement in teaching, assessment and course planning. Programmes must have in place systems to support and enable users of social care services and carers to make an effective contribution in all these areas. (General Social Care Council, 2009, p. 23, paragraph 61)

The programme was originally commissioned by a regional employers' consortium, who were themselves informed by the voices of service users and carers, and works closely with a number of local authorities and other agencies in a partnership which is felt to be very effective. Agency partners are involved fully in all aspects of the programme, from development, review and management (through a Stakeholder Board), to planning and delivery of teaching and learning, candidate selection and assessment, and in quality assurance mechanisms. The review process of the programme involves ongoing assessment of whether the programme is fit for purpose, 
not only in meeting the aims of the PQ Framework - to 'ensure that post-qualifying education and training improves the standard of social work practice' (General Social Care Council, 2009 p.4), but also in meeting the specific training needs of the agencies who sponsor candidates on the programme. Such partnership working in programme development has led to Higher Specialist Award level modules being developed at the University, such as Leadership and Management in Safeguarding, to meet training needs specifically identified by a partner agency.

Service user participation in developing practice and service delivery has been a major theme in the learning outcomes set for the PQ programme, and Arnstein's (1969) model of a ladder of participation has underpinned our teaching in this respect. In addition, service users and carers have been involved in design, delivery and assessment of teaching and learning, in the Stakeholder Board and in the programme's Diversity Advisory Group. Involvement of service users and carers in the teaching and learning strategy for the programme has developed over some time; it could be considered to have reached level three (growing involvement) on the 'Ladder of Involvement' (Balman, 2007 p.9) This is not to say that a higher level is not aimed at; the programme is working towards level four (collaboration) but acknowledges that multiple barriers exist to full and effective involvement (Balman,2007, Gutteridge and Dobbins, 2010); practical barriers of time and ensuring that the voices of the 'rarely heard' are included being but two. The Specialist Award, which is taught mainly at the University on a part-time (day release) basis, has had direct service user educator input since 2007 - however the Consolidation module is mostly cotaught with agency trainers at agency venues, and individual agencies have used differing models of service user input in the delivery of this module: either direct input through group teaching sessions or theatre presentations, or indirect input through letters from service users, or video presentations. In addition to this, it has always been a feature of both Specialist and Consolidation assessment of candidates, that they are directly observed in practice with service users and carers, who are invited to give feedback on the candidate's practice to the candidate's Practice Mentor Assessor (PMA) who undertakes the observation. This service user feedback forms part of the report that evaluates the candidate's practice. This last form of input fits into Balman's (2007) model at the level of 'limited involvement'..'asking people who use services to comment on PQ candidates' performance' (p9) but is nonetheless an important part of the assessment process, as it relates directly to the candidates' need to reflect on and develop their own individual practice.

A significant body of literature addresses the benefits of service user educator input both for the service users themselves and representative organisations (Barnes and Mercer, 2003; Carr, 2004; Levin, 2004; GSCC, 2005; Shaping Our Lives, 2007). Research has also considered the need for more effective evaluation of the impact of PQ education (Doel et al, 2007; Higham, 2009; Preston-Shoot, 2005). Reviews of the literature have found very little evidence for outcome evaluation related to service user and carer input in social work education (Carpenter, 2005; 2011; Matka et al, 2009). 
In a review article, there was a good body of literature looking at the involvement of service user educators in social work qualifying education, (Brown and Young, 2008), but less regarding involvement in PQ child care education; there was more research focused on PQ mental health provision (Bailey, 2002, Brown et al, 2008)

Programme stakeholders had demonstrated a strong commitment to the input of service user educators within the PQ programme, and had expressed optimism that user/carer involvement on the programme could influence a more inclusive working relationship between service users and workers. It was felt that positive benefits for service users were only likely if service user involvement formed an integral part of social work learning and practice, and not if involvement was undertaken as a token gesture. However, on the other hand, there were also some expressions of concern from the stakeholders that hearing negative experiences of social work involvement could damage confidence in practice for candidates, reflecting Yip's (2006) notes of caution on the potential dangers of self-reflection.

\section{A collaborative research project}

In 2009, the Division of Social Work, Health and Social Care and Counselling researched the impact of service user and carer input to PQ education on service user outcomes, with funding from the General Social Care Council. In the context of the discussions with PQ stakeholders, the PQ teaching team felt that this was a timely request, as well as an opportunity to develop our skills as researchers alongside colleagues from the division with more research experience. Representatives of Advocacy in Action, a local service user organisation who had been involved with both the PQ and Social Work degree programmes, were invited to join the project, and from the first meeting, a small group of users of services and former PQ candidates were also invited to work as research assistants. The steering group for the project elected a service user educator of many years' experience as Chair, and The Equally Experienced Research Group was formed. We planned from the outset that methodology, data collection, analysis and production of the report would all be a collaborative process along the principles of action research (Hart and Bond, 1995), to enhance the experience, and outcomes, for all the participants.

The question we were asked to look at (Equally Experienced Research Group, 2011 p.4) was, 'What difference does it make to end service users, having service users involved in the design and teaching of the PQ programme?' An important consideration was the academic members' work at the time to improve the overall evaluation of the division's teaching, acknowledging that evaluation of teaching and learning should be at more than the happy-sheet reaction level (Kirkpatrick, 1994 cited in Chapman, 2009). 


\section{Methods}

A three-pronged methodology enabled a triangulation approach to data gathered (Denzin,1970,1978): a) postal questionnaires; b) analysis of reflective commentaries in PQ Consolidation portfolios and c) face to face semi-structured interviews with operational team managers who had supported candidates through PQ. The surveys consisted of a short series of open questions for reflective comment, and were sent to present and past PQ candidates.

Our questionnaire return rate was 11\% (33 from 300); we might have expected a higher return, but Powell and Orme (2011) suggest that emailed questionnaires with tick-box responses and space for related comments may be a more successful way of obtaining responses from busy social work professionals, so that is a useful lesson learned.

Candidates are asked to write a reflection on their practice and values at the start of the Consolidation module, and then a further commentary reflecting on their learning over the course of the module; this gives at least some indication of the programme learning outcomes being met, and the development of skills, knowledge and values. In considering the commentaries, a five-point framework was used, focusing on feelings, thoughts, making links with practice development, learning and commitment with reference to service user involvement.

In the manager interviews, they were asked to comment on their understanding of their agency's partnership with the University in PQ provision. In addition, they were asked what feedback they had received from their candidates about service user input to the programme, what differences they had observed in their candidates' practice in respect of engagement with service users and carers and whether learning had been shared within the team. They were also asked to comment on any added benefit they had seen for their team in respect of engagement with service users, what they might anticipate as benefits to service users as a result of service user educator input in $\mathrm{PQ}$, any examples of actual benefits to service users that they had observed, and what might assist or hinder implementation of these benefits. Finally, they were asked to comment on how they individually, as a team or agency used service user feedback in evaluating service outcomes - and whether there was anything else they would like to add.

Four of our partner agencies, all County local authorities to give some equivalence, were approached to participate. Postal questionnaires were returned by staff from all four agencies. However, we were only permitted to view the reflective commentaries, and interview managers, from three out of the four agencies. 


\section{Findings}

Findings from the questionnaires from the four agencies identified three different perceived levels of service user input: individual service user feedback on practice, service user educator input to teaching and service user perspectives found in research or case studies. Two areas of impact were described: intrinsic (impact on awareness, personal values, reflection, feeling defensive) and extrinsic (impact on skills, approach and practice).

The greatest impacts on the respondents were reported where service user input was direct, in teaching. In contrast, input from the drama group in which the experiences of service users are acted out for the PQ participants, was felt to have little impact by respondents who had experienced it. Reflective commentaries from Consolidation module portfolios provided interesting reading. Whilst not all commentaries made any reference at all to service user involvement in their teaching and learning experience, several key themes emerged. Firstly, there was evidence of existing good practice and a sound value base expressed in both initial and final commentaries; much comment was made on the importance of open and honest communication in delivering practice that would optimise service user outcomes.

Whilst the group who had experienced the drama presentation made little comment on the impact of service user input, in other samples positive impact on practice was felt to arise from hearing directly from service users:

During one session, two young ladies joined the group to discuss their experience of being 'looked after', ..... The service users were able to be candid without fear of repercussion as their identities remained anonymous. This session had the greatest impact on me; I was able to consider their accounts in order to apply Gibb's 'reflective cycle' and improve my current and future practice. (Candidate B, Sample B: Equally Experienced Research Group, 2011 p.31-32)

This improved ability to integrate service user perspectives into the reflective cycle, increased skills in critical evaluation of outcomes and understanding of how practice and services can be developed, was another positive theme; some candidates wrote of sharing their learning in team meetings to help to develop practice more widely.

On a more negative but maybe pragmatic note, many candidates reflected on the impact of highly pressured work environments and sometimes overwhelming caseloads on practice development.

Examining portfolios gave an opportunity to consider other data of relevance. Service user feedback was commented on in places, showing some good practice: one candidate reflected on written feedback from one of her service users responding to the question, 'Did you feel that (candidate A) listened to you and heard what you were saying?' with 'Yes, I knew this was true as in subsequent meetings she would refer to what was said previously and would have acted on it.' (Candidate A, Sample 
C: Equally Experienced Research Group, 2011 p.33). Practice Mentor Assessor reports also reflected candidates' valuing of service user perspectives: 'she (candidate D) expressed immense value and importance in speaking with children and ensuring they have a voice' (Candidate D, Sample C: Equally Experienced Research Group, 2011 p 33)

The third group of data collected were from semi-structured interviews with candidates' managers from three of the agencies. Managers were generally unaware of the extent of service user educator input to PQ teaching; indeed, their engagement with their staff's PQ training was variable despite the agreed understanding that candidates had reflected on their learning in portfolios and that their managers were required to read and verify them. However, there was some acknowledgement that PQ candidates raised awareness of service user engagement as a focus for practice and spread development of values though their teams, and some were able to relate this to service user educator input.

The responses of some managers manifested some concerns about being outstripped in knowledge by PQ candidates whom they supervised. This was considered to be a clear barrier to developing learning and developing services. Although the managers identified the need to develop meaningful ways of gaining feedback from service users, as well as the need to develop methods of using the feedback in order to inform service delivery, they acknowledged that this actually did not happen enough currently. We gained a picture of understanding of the role of user participation in service development, but patchy organisational implementation of this as a strategy. One view was that whilst service user feedback may officially be welcomed by social workers, the actual receiving of negative and critical feedback about service provision 'can be disheartening for workers who already feel trapped between providing what service users want, whilst adhering to budget constraints and government targets' (Equally Experienced Research Group, 2011 p.30).

\section{Discussion}

So, what did our findings tell us? Did they match what we as the PQ teaching team had expected from our experience of previous discussions with candidates, PMAs and stakeholders? Were there any unexpected findings? In terms of our original question, we got at least a partial answer. First, candidates generally felt they had a positive experience of the direct input of service user educators in their PQ programme, and were able to link this to their practice development. Our prediction is that as a result of this PQ experience, candidates' own service users will receive a better service as a result. This could also be an area for further follow-up research.

We knew from reading and experience that $\mathrm{PQ}$ education is a valuable experience for practitioners, in developing their practice skills and knowledge (Doel et al, 2008, 
Ayres, 2011). So our expectations in terms of beneficial impact of service user educator input, and the learning and practice development of candidates, were met.

The impact on individual practitioners (and in many cases their teams) is positive and significant, as the primary driver for service user educator involvement in developing and delivering practitioner training and education is 'the anticipation that it will produce practitioners capable of delivering improved and more relevant outcomes for users and their carers' (Tew et al, 2004 cited in Lathlean et al, 2006 p.733). Future plans for the programme as it moves into the post-GSCC era should therefore continue to develop the involvement of service user/carer educators in all levels of programme development, including evaluation. Furthermore, the giving and receiving of service-user feedback should be embedded and enabled within all levels of Post-Qualifying learning and every aspect of agency work; Stickley et al (2011) found benefits to both students and service users in the feedback process of service user review of students' practice, with indications for the need for further development of the way in which feedback is sought.

Genuine feedback is undoubtedly the best way to know how I am perceived by service users. And this is the best way to know how to improve service delivery. (PQ candidate: Equally Experienced Research Group, 2011 p.32)

An unexpected result was the contrast between the impact of direct teaching by service users and the drama groups. The expression of service user views in fiction and drama is thought to encourage 'compassionate engagement with practice' (Taylor and White, 2006 p.949). This links to Forrester et al's (2008a; 2008b) work on the role of empathy in promoting effective engagement with service users, leading to improved outcomes. However the drama groups in this small study did not have the significant impacts which the service user voices did.

There were other unexpected findings. For example, we had not expected from our research that the responses we received would highlight:

1. significant gaps in practical and informed support for PQ candidates within their agencies;

2. the number of areas where barriers to learning and development could exist and would need to be addressed; and

3. some perceived threat expressed by managers when considering their candidates' increased levels of knowledge and understanding.

Also unexpected was the managers' responses in the interviews, that they had not always read the portfolios or learned about the benefits of training and thus, that the development needs of the PQ practitioners were not a part of reflective supervision (Morrison, 2005; Brown and Rutter, 2006)

Unexpected outcomes also included the discrepancies between the agencies' 
and the university's perspectives about the importance of service user input as a recommended strategy for improving empathy of the PQ social workers and ultimately service delivery to other service users. To uncover such gaps, through the responses, in evaluation of services being conducted at an organisational level was a surprise. However, maybe we should not have been surprised by this, for as Bogolub argues, 'qualitative research seems particularly likely to raise such unanticipated questions' (2010 p9). These unexpected results can lead to new considerations and new strategies to address the identified gaps.

\section{Implications for practice}

The importance of effective evaluation of service user involvement in PQ social work education was a key message from our findings, both in relation to our own programmes, and the services provided by our partner agencies. As educators, we need to consider all aspects of evaluating the practice of our post-qualifying candidates, from the start of the programme to the end, so that base-line assessment can inform summative assessment of learning outcomes and practice development (Bailey, 2002). In doing this, we need to continue, as a Division within the School of Social Sciences, to develop our understanding and practice of programme and research evaluation, particularly impact assessments.

Agencies may also need to be a bit more proactive in evaluating outcomes of their services. Interest in improving outcomes of service evaluations could lead to agency requests for additional PQ staff training and development from the University. Given the increasing role of HEIs in provision of CPD at different levels for social care agencies, there may be a value in increasing collaborative work with agency partners to develop strategies for the evaluation of service outcomes and Training Needs Assessments. If agencies are to promote social justice by ensuring that their services truly optimise the life chances and wellbeing of their service users, to act as real agents of social change, then for universities to work with partner agencies to strengthen and develop service evaluation strategies should be a priority for the field.

It is beyond the scope of this paper to consider the variety of evaluation models and methods available for agencies to use in developing best outcomes in practice and education, but several models appear likely to be useful. The realist evaluation paradigm (what works, for whom and in what contexts) (Kazi, 2003) is a model we teach to PQ candidates in terms of developing their evidence-informed practice. For 'beginning' researchers, we use this as a strategy in practice to develop skills in multivariate analysis. Maxwell et al (2012) discuss the use and value of secondary analysis of panel studies - longitudinal population studies - in measuring outcomes in social care services. Whilst these data are collected generally on a national basis, and therefore are hard to relate to specific social care agencies or practitioners, they 
can offer a benchmark range of outcomes against which local results can be compared.

Evaluation models and methods, particularly focussing on those developed in collaboration with service user groups, would be areas of research that we could plan for in the future. Barnes et al. (2000) (cited in Carpenter, 2011 p.129) used 'a questionnaire to determine user-defined outcomes of post-qualifying education'; they found that these outcomes focused on changes in attitudes, skills and values, which are level 2 outcomes in Kirkpatrick's learning evaluation model (Kirkpatrick,1994, cited in Chapman, 2009). Social Care professionals, on the other hand, might look for outcomes being related to well-being, self-esteem, changes in behaviour and achievement (level 4). Achieving a balance between these two foci would be a valid area for future research in collaboration with both agencies and service users/carers. Whilst a broad national picture would be useful, local research under the aegis of Knowledge Transfer Partnerships might be a route that could be taken.

Possibly PQ training and education specifically developed for senior level managers could address some of the unexpected findings. Managers should be supported to have expert levels of service evaluation and advanced practice knowledge in order to be effective leaders and supervisors of staff. And an important part of practice knowledge, if you work effectively in partnership with your service users, is the knowledge that service users themselves hold (Levin, 2004; Trevithick, 2008). 'Leadership in this area of professional development might involve encouraging senior members of the social work research community to play key roles in facilitating such opportunities.' (Powell and Orme, 2011 p.1582)

\section{Conclusion}

Our small study into the impact of service user input in Post-Qualifying social work education took us into areas we had not originally imagined, with implications for the development of evaluation strategies both within the University and in the wider context of social care providers. Nearly a decade ago, Munro (2004) argued that evaluation of social work service provision through standard audit techniques risked focussing on service output at the expense of evaluating outcomes for service users, and speculated that this might remain an issue as formalised managerial approaches took stronger organisational hold. Certainly audit and evaluation through performance indicators focused on reaching standardised targets, and the current management of social care agencies as businesses rather than as agents of social change does little to redress this balance. We hope we have showed that there is potential for evaluation of both individual practice and outcomes for service users which can, in response to Munro's more recent work (Munro 2011), provide a platform for research partnerships between academics, organisations and service users and carers. 


\section{References}

Arnstein, S. R.(1969) A ladder of citizen participation. Journal of the American Planning Association, 35, 4, 216-224

Ayres, S. (2010) Undertaking an Audit And Evaluation of PQ in Six London Local Authorities. London: Skills for Care

Bailey, D. (2002) Training together, part two: The evaluation of a shared learning programme on dual diagnosis for specialist drugs workers and Approved Social Workers (ASWs). Social Work Education, 21, 685-699

Balman, M.(2007) Developing and Delivering the New PQ framework: Involving people who use services and carers, Leeds: Skills for Care

Barnes, C., and Mercer, G. (2003) Research Review on User Involvement in Promoting Change and Enhancing the Quality of Social Care' Services for Disabled People, Centre for Disability Studies, University of Leeds

Bogolub, E. (2010) The Obligation to bring about Good in Social Work Research: A New Perspective, Qualitative Social Work 9, 9, 9-15

Brown, K., \& Rutter, L. (2006) Critical Thinking for Social Work, Exeter: Learning Matters

Brown, K., and Young, N. (2008) Building Capacity for Service User and Carer Involvement in Social Work Education. Social Work Education, 27, 1, 84-96

Brown, K., McCloskey, C., Galpin, D., Keen, S., Immins, T. (2008) Evaluating the impact of post-qualifying social work education. Social Work Education, 27, 8, 853-867

Carpenter, J. (2005) Evaluating Outcomes in Social Work Education. Discussion Paper No.1. London and Dundee: Social Care Institute for Excellence (SCIE) \& Scottish Institute for Excellence in Social Work Education (SIESWE).

Carpenter, J. (2011) Evaluating Social Work Education: A Review of Outcomes, Measures, Research Designs and Practicalities. Social Work Education, 30, 2, 122-140

Carr, S. (2004) Has Service User Participation Made a Difference to Social Care Services? SCIE Position Paper 3. London: SCIE/Policy Press

Chapman, A. (2009) Donald Kirkpatrick's Learning Evaluation Model 1959 (online) at http:// www.businessballs.com/kirkpatricklearningevaluationmodel.htm (Accessed 1 February 2012)

Denzin, N. (1970) The Research Art in Sociology, London: Butterworths

Denzin, N. (1978) Sociological Methods: a sourcebook (2 ${ }^{\text {nd }}$ edition), New York: McGraw-Hill

Doel, M., Carroll, C., Chambers E., Cooke, T., Hollows, A. Laurie, L. \& Nancarrow, S. (2007) Developing measures for effective service user and carer participation. SCIE Stakeholder Participation Position Paper. London: SCIE

Equally Experienced Research Group (2011) The Involvement Of Service-Users In Post Qualifying Childcare Teaching and Learning: Does It Make A Difference? Nottingham: Nottingham Trent University

Forrester, D., McCambridge, J., Waissbein, C., Emlyn-Jones, R. and Rollnick, S. (2008a) Child Risk and Parental Resistance: Can Motivational Interviewing Improve the Practice of Child and Family Social Workers in Working with Parental Alcohol Misuse?. British 
Journal of Social Work, 38, 1302-1319

Forrester, D., McCambridge, J., Waissbein, C. and Rollnick, S. (2008b) How do child and family social workers talk to parents about child welfare concerns?. Child Abuse Review, $17,1,23-35$

General Social Care Council, 2005, Working towards full participation, (online) www.gscc.org. uk/publications (accessed 20/5/2009).

General Social Care Council (2009) Post Qualifying Framework for Social Work Education and Training, London: GSCC

General Social Care Council (2010) Raising Standards: Social work education in England 200809, London: GSCC

Gutteridge,R., and Dobbins, K (2010) Service user and carer involvement in learning and teaching: A faculty of health staff perspective. Nurse Education Today, 30, 6, 509-514

Hart, E., and Bond, M. (1995) Action Research for Health and Social Care: A guide to practice. Open University Press: Buckingham

Higham, P. (2009) Post Qualifying Social Work Practice, Sage: London.

Kazi, M. (2003) Realist Evaluation in Practice. British Journal of Social Work, 33, 803-818

Lathlean, J., Burgess, A., Coldham, T., Gibson, C., Herbert, L., Levett-Jones, T., Simons, L. and Tee, S. (2006) Experiences of service user and carer participation in health care education. Nurse Education Today, 26, 8, 732-737

Levin, E. (2004) Involving Service Users and Carers in Social Work Education, London, Social Care Institute for Excellence (SCIE)

Matka, E., River, D., Littlechild, R. and Powell, T. (2009) Involving Service Users and Carers in Admissions for Courses in Social Work and Clinical Psychology: Cross-Disciplinary Comparison of Practices at the University of Birmingham. British Journal of Social Work, 40, 7, 2137-2154

Maxwell, N., Scourfield, J., Gould, N., Huxley, P. (2012) UK panel data on social work service users. British Journal of Social Work. 42, 165-184. Advance Access publication April 27, 2011

Morrison, T. (2005) Staff Supervision in Social Care: Making a real difference for staff and service users. ( $\left.3^{\text {rd }} \mathrm{Ed}\right)$. Brighton: Pavilion

Munro, E. (2004) The Impact of Audit on Social Work Practice. British Journal of Social Work 34, 1075-1095

Munro, E. (2011) The Munro Review of Child Protection: Final Report - A child-centred system. London: Department for Education

Powell, J. and Orme, J. (2011) Increasing the Confidence and Competence of Social Work Researchers: What Works? British Journal of Social Work 41, 1566-1585 Advance Access publication March 19, 2011

Preston-Shoot, M. (2005) Demonstrating Quality in Post Qualifying Education'. Contact News and Views, GLPQETC: London. (pp.8-9)

Shaping Our Lives (SOL), (2007) Developing social Care: Service users driving culture change, London, SCIE

Stickley, T., Stacey, G., Smith, A., Betinis, J., Pollock, K. and Fairbank, S. (2011) Developing 
a service user designed tool for the assessment of student mental health nurses in practice: A collaborative process. Nurse Education Today, 31, 1, 102-106

Taylor, C. and White, S. (2006) Knowledge and reasoning in social work: Educating for humane judgement, British Journal of Social Work, 36, 937-954

Trevithick, P. (2008) Revisiting the knowledge base of social work: A framework for practice. British Journal of Social Work 38, 1212-1237

Yip, K.-S. (2006) Self-reflection in reflective practice: A note of caution. British Journal of Social Work, 36, 777-788 